\title{
AN INTERPLAY OF SELF-EFFICACY IN PURSUIT OF A TERTIARY QUALIFICATION: A CASE STUDY OF A BLACK MALE
}

\author{
D. Alexander \\ Discipline of Psychology \\ University of the Witwatersrand \\ Johannesburg, South Africa \\ e-mail: dinah.alexander@wits.ac.za
}

\section{ABSTRACT}

This case study explores the perceptions of a middle-aged, previously disadvantaged South African male regarding his pursuit of a higher education qualification. A qualitative, exploratory, descriptive and contextual research design was used. A narrative inquiry, utilizing a semistructured interview schedule was used to interview the participant. The themes that emerged centred on external and internal barriers that the participant perceived to impact on his pursuit of a higher education qualification. The career counselling intervention based on the Social Cognitive Career Theory as a form of a postmodern theoretical intervention appears to have been helpful to this participant.

Keywords, middle-aged, pursuit of a higher education qualification, barriers, poverty, rural, selfefficacy, outcome expectations

Research studies found that socio-economic variables like poverty, absent parents, a disadvantaged rural context, chronic health problems of parents, low educational level of parents, unemployment of parents, parental abuse and neglect, substance abuse, lack of mobility, exposure to inadequate school facilities and practices and a lack of role models can have a negative impact on the development of self-efficacy in children (Leroy and Symes 2001, as cited in Pellino 2007). Bandura (1986; 1993; 1997) defined self-efficacy as the levels of confidence individuals have in their ability to execute courses of action or attain specific outcomes.

Studies were conducted to investigate the impact of these socio-economic variables on children through to their early adulthood with a particular focus on the development of their self-efficacy and pursuit of a higher education qualification. It was established that entry and successful completion of tertiary studies and the subsequent successful entry into the world of work for individuals from disadvantaged rural contexts was limited and stacked with major challenges (Cosser 2010; Maree 2015). One study found that the non-completion rate of 37 per cent at historically White institutions was close to half of that at historically Black institutions 
where the rate was 62 per cent (Bhorat, Mayet, Visser, Cosser, Breier and Letseka 2010). Historically Black institutions had more individuals affected by the abovementioned socioeconomic variables.

Some of the challenges that students affected by the abovementioned socio-economic variables faced at tertiary institutions were high drop-out rates, failures and repeating of academic courses or changing the direction of study fields, resulting in challenges related to the successful completion of tertiary qualifications within a required time frame and subsequently finding gainful employment (Scott, Yeld and Henry cited in Murray 2014).

Previous research focused mostly on the impact of these socio-economic variables on the external disadvantaged context, whilst ignoring the psychological impact, like the influence thereof on the development of self-efficacy. Self-efficacy is regarded as one of the most underresearched psychological variables that may impact on students' success at tertiary level and their subsequent career trajectories (Pajares 1996; Creed, Patton and Prideaux 2006).

The lack of research into self-efficacy is more profound for middle-adulthood individuals who failed due to the abovementioned challenges by dropping out, failing and repeating academic courses or changing the direction of study fields or not completing a tertiary qualification within a required time frame and who finally seek counselling at this stage in their pursuit of a higher education qualification.

The absence of research information on affected individuals endeavouring to make a comeback, as abovementioned, motivated the following research aims:

\section{AIMS}

- $\quad$ To conduct a case study about the challenges, perceptions and narrated experiences of a particular Black male, in middle-adulthood, who has been affected by the abovementioned socio-economic variables and failed in his pursuit of a tertiary qualification.

- To explore the application of the Social Cognitive Career Theory, by focusing on selfefficacy, on the tertiary educational aspirations of the above-mentioned participant as an overarching aim.

- $\quad$ To explore how a person's background, their personal attributes and behaviour work together to produce specific outcomes, as espoused by Social Cognitive Career Theory’s (SCCT’s) concept of triadic reciprocality.

\section{LITERATURE STUDY}




\section{Self-efficacy: A brief overview}

According to SCCT self-efficacy is informed by Personal performance accomplishments; Vicarious (Modeling) learning; Social / Verbal persuasion and Physiological arousal /states and reactions. The optimal development of self-efficacy could foster the creation of mindsets characterized by (i) self-awareness, (ii) awareness of the deep seated impact of internal and external factors on all aspects of life inclusive of career choice and decision making; and (iii) awareness of their innate ability, self-agency, to identify available options which could assist them in overcoming real or perceived barriers on their pursuits and completion of a higher education qualification (Bandura 1993; Bandura 1994).

Perceived barriers hamper the optimal development of individuals' self-efficacy beliefs, fostering mindsets which lack the characteristics cited above. Perceived barriers are contextspecific and may be internal or external. These under-developed self-efficacy expectations can in turn impact negatively on an individual's general, academic and career development with far-reaching consequences such as foreclosed or entrenched career development. There are many perceived or felt external contributory contextual factors within disadvantaged contexts. The premise for this study is that these factors can hamper an individual from a disadvantaged context’s self-efficacy to pursue a higher education qualification (Bandura 1993; Bandura 1994).

Perceived barriers may change with the challenges encountered in the different development phases. For example, traditionally middle adulthood brings additional challenges of being a spouse, parent and provider. According to Bandura (1994) self-regulatory efficacy is required in this stage to stabilize a sense of efficacy in major areas of functioning. Stability is often shaky because of new challenges in the form of technology, re-appraisals, competing for promotions, status, work itself and social comparisons with young competitors.

SCCT acknowledges that by telling their story and allowing the client to be the expert, personal agency can be developed which would facilitate personal and academic growth, which would lead to a higher sense of self efficacy (Bandura 1993; Bandura 1994).

According to SCCT, there is a feedback loop resulting in self-awareness and shifts which provide individuals a platform to utilize experiences to evaluate and self-reflect, resulting in a re-direction of mindsets, shifts in self-efficacy, goals, outcome expectations and an overall growth in personal career development (Bandura 1993; Bandura 1994).

\section{CONTRIBUTORY CONTEXTUAL FACTORS IMPACTING ON SELF-EFFICACY IN DISADVANTAGED CONTEXTS}




\section{Poverty}

Poverty per se may not be a risk factor, but its impact may be exacerbated by compounding factors as indicated above (Leroy and Symes 2001, cited in Pellino 2007). Significant to the development of optimal self-efficacy are the many challenges that poverty may impose thereon. Poor parents affected by these compounding factors have less capital. This means they cannot afford to give their children a richer experience, launch them onto trajectories that will raise their self-efficacy through exposure to child-care, enrichment programmes, books, electronic support programmes, role modelling, self-efficacious communications or teaching them necessary coping strategies (Schunk and Meece 2006; Mok and Flynn 1997). These deficiencies can lead to ineffective meaning making of experiences relating to self, their development and perceptions of their self-efficacy as individuals from disadvantaged contexts.

The effects of urban poverty may vary greatly from that of rural poverty. Rural poverty areas are characterized by single guardian households and families often have less access to services, support for disabilities and quality education opportunities (Tacoli, McGranahan and Satterthwaite 2015).

An Ethiopian study found that: fatalistic beliefs prevailed in a substantial amount of poor rural households; indicators consistent with a small aspiration gap and low self-efficacy were evident; participants had limited information from the outside world and used their immediate neighbours, in similar circumstances as themselves, as role models causing them to have a restricted world view; participants demonstrated an external locus of control and participants did not take advantage of presented opportunities or create new ones from the challenges faced (Bernard, Dercon and Taffesse 2011).

The lack of locus of control and poverty seem to be inextricably linked. SCCT posits that the extent to which an environment is controllable is essential for self-efficacy. Thus the extent to which personal-efficacy can bring about change by perseverance and effort enhances selfefficacy. Constraints and lack of opportunities to exercise self-efficacy to modify the environment leads to lowered aspirations and performance (Bandura 1993).

According to Bandura (1993) the perceived lack of control of access to institutions of higher learning because of poverty may lower self-efficacy beliefs of those learners from poor backgrounds that they can succeed. Accordingly, they may not apply for entry or attempt to succeed or even dream of such careers that require a tertiary education

\section{Rural context}


Zinta (2006) found that urban students had a higher perceived self-efficacy and also outperformed rural students in a problem-solving task. The lower performance of the rural students was ascribed to their quality of education and less exposure to enriched environments. The higher performance of the urban students was ascribed to better quality of education, availability of information from multi-media, their educated families and supportive peer groups.

Maldonado et al. (2008) found that the consumption of alcohol and tobacco was lower in rural students with a higher perceived self-efficacy. They warned that these results be treated with caution since the rural student's consumption may have been lower due to poverty since they may have lacked money to acquire more of these substances to consume.

\section{Systemic risk factors}

In the United States of America those with low socio-economic status are invariably expected to be Hispanic or African American (Borman and Rachuba 2001). Borman and Rachuba (2011) warned that this risk of failure is often systemically supported by education departments that allocate inequitable and poor resources to areas which are predominantly poor, thus perpetuating this prophesy.

In South Africa Spaull (2012) criticized the national education system with its low quality education with a high and lenient grade progression until grade 11 as the root cause of the lack of systemic access to tertiary education for learners from disadvantaged contexts. Modisaotsile (2012) concurs that several systemic risk factors impact on poor children's education at all levels in South Africa.

\section{Parents' chronic illness}

Research confirmed that the chronic illness of parents, impact negatively on their children's self-efficacy. This stems from the inability of the affected parent to model self-efficacious behaviours to their children due to the limitations created by their physical condition (Callander and Schofield 2015)

\section{Absent fathers}

Sylvester (2010) found that children with an absent father are: likely to grow up in an environment characterized by financial instability and a lack of family resources; are less likely to do well at school, finish college or hold down a job and likely to be more aggressive and becoming youth at risk due to challenges involving discipline issues at home and at school. 
According to Madhavan, Townsend and Garey (2008) the lack of co-residency with a father figure does not necessarily indicate a lack of support since many absent fathers still provide financial support to their children. It was the intangible aspects of the relationship, like emotional support, that suffered. These findings are significant for South Africa where the migrant labour system from the Apartheid era, was instrumental in many black children growing up with absent fathers.

\section{METHODOLOGY}

\section{Research design}

A qualitative paradigm was utilized. This paradigm focuses mainly on understanding and providing a meaningful description of human experiences and behaviors (Neumann 2003) within a certain social context by allowing the researcher to conduct research that is interactional and informative (Fossey, Harvey, McDermott and Davidson 2002) because human beings are social beings, constantly trying to make sense of their world (Shank 2002).

\section{Sampling}

Sampling in qualitative research is concerned with information richness, providing a thick description of the phenomena being studied irrespective of the number of participants (Fossey et al. 2002). This study employed a non-probability, purposive sampling strategy using the following criteria: the participant must be English speaking; must have attempted to pursue a higher education qualification and be an adult male from a previously disadvantaged context. The sample choice was based on feasibility, accessibility and convenience.

\section{Procedure of data collection}

\section{Instrument}

Data collection was through a semi-structured interview, using an interview guide (Greenstein, Roberts and Sitas 2003), which encouraged the participant to tell his life story in a way that the interviewer gained insight on his experiences, feelings, social environment, views and beliefs (Fossey et al. 2002).

The interview was audio-recorded to allow the researcher to listen to the interviews repeatedly to identify information that was missed before and to report the data obtained more accurately (Breakwell, Smith and Wright 2012). 


\section{Ethical considerations}

An information sheet, containing information which was also conveyed verbally, was handed to the participant before the interview. Written consent was obtained from the participant to participate and audio-record the interview. Measures were enforced to ensure the participant's safety. These measures included that: participation in the research study was voluntary; he could refuse to participate at any point without any penalties; there would not be any advantages or disadvantages for participating and he had the right not to answer any question that he felt uncomfortable answering. A debriefing session was conducted after the interview.

The audio data was stored securely and made accessible only to the researcher, coresearcher and the scribe. No negligence was involved and the data was not distributed harmfully. Once the research is completed, the data will be destroyed.

A summary of the results will be given to the participant upon request. All direct quotes from the participant were sanitized and made untraceable to him although anonymity could not be ensured. The participants' right to welfare, dignity and privacy is maintained throughout. Informed consent was obtained for conference presentation of the results and the publication thereof in a journal.

\section{Procedure}

Three interventions were implemented. A postmodern appreciative enquiry approach, emphasizing rapport building, was utilized. The participant had undergone 6 sessions based on a narrative approach, allowing him to tell his life story. He had also undergone psychometric career assessments to augment his career decision-making process. A semi-structured interview was conducted with him thereafter. Half way through the interview, the term self-efficacy was clarified.

The researcher kept a reflexive journal to document her thoughts, feelings and actions throughout the research process. An independent transcriber transcribed and analyzed the data.

\section{Data analysis}

The transcribed data was analyzed using thematic content analysis (Fossey et al. 2002) by evaluating, identifying, and reporting the presence or repetition of particular themes or phrases in a set of data (Braune and Clarke 2006). Inferences were drawn from the data utilizing the themes and phrases (Babbie and Mouton 2001). 


\section{RESULTS}

Two main and several sub-themes emerged. The overarching themes were related to:

1. The subject's initial narration of how external and internal barriers impacted his selfefficacy beliefs and subsequent behaviours.

2. The second theme related to a sense of awareness and insight, which led to a shift towards personal agency.

\section{BARRIERS}

Two main overarching themes emerged namely: barriers and the pursuant shift.

Four sub-themes further emerged from the barriers, namely external and internal barriers impacting on the first attempt to acquire a tertiary qualification and external and internal barriers impacting on the attempts to acquire a tertiary qualification in middle-adulthood.

Two sub-themes emerged from the shift: an internal shift and a shift in the perception of contextual factors.

\section{External barriers impacting on the first attempt to acquire a tertiary qualification}

Poverty, exacerbated by low educational level of parents, low income of parents, absence of father and parental chronic ill-health.

\section{Low income of parents and affordability}

... My parents and I wouldn't even wanna question them, ... Why can’t I have this? Why can't I have that? I could literally see that they couldn't ... it was more of affordability.

... My peers would be singing: I'll be going to this varsity ... that Technikon. I couldn't really respond ... I wasn't going to go anyway because ... of my parents’ affordability ...

We ... heard the people who were ... already in varsity talking about how much the books were, the fees and food ... and I would think ... where do I think mummy would get that money from ...

\section{Regarding parental education}

It’s very low. My father ... he had ... which is today Grade four.

... my mother I think ... she had ... which is today Grade 6.

\section{Parental chronic ill-health}

... after she was diagnosed with Asthma ... she couldn’t work anywhere ... 


\section{The absence of the paternal parent}

I lived with my mother ... because my father used to work ... in mines then ... even today he's still ... NOT ... staying at home, he still works in Secunda and my mother's at home ... with my little brother.

... from my mother's side ... If we didn't go to school ... we want a better future for ya'll ... so therefore you need to go to school ... She has supported all she could.

\section{External barriers stemming from growing up in a rural area}

\section{These were lack of information and exposure}

And ... lack of electronical equipment ... lack of information ...

... a Grade 10 student from home and you take a Grade 10 student from here ... the urban kid from here is ... more able to trying and doing things, ... because of the exposure ....

\section{Peer pressure}

... you have this freedom ... that's what made me fail my N3 ... and my N1 .... My mindset changed direction .... I began going out with friends, ... that's when peer pressure gave in .... I started smoking ... having booze. ... The results were, ... bad.

\section{The systemic challenges of the educational system}

I was an A student. The results would be called by names ... me, Number 1 ... Then my friend $\mathrm{T}^{*}$ would be number one ... Grade 4 ... we were both number 1's ... Grade 5 I was number 1 he was number 2, Grade 6 ... he was number 1, I was number 2 ..., we were forever up there, but ... unfortunately when I got slightly older the results dropped.

\section{External barriers impacting on attempts to acquire a tertiary qualification in middle-adulthood}

These were: restricted access to tertiary institutions and the requirement for tertiary qualifications for career advancement.

Apply through UNISA ... and for some reason I didn’t qualify for a degree .... They said that I can do ... bridging ... they call it access program .... If one fails access then the $2^{\text {nd }}$ option was ... a diploma. ... I'm ... hoping that at least something can qualify me to study.

I think it's very important for one to pursue it. Especially now that ... whether you've got experience or not, they will still, for better employment, they will still say, that piece of paper we want. For example a degree ... or a diploma ... or a $2^{\text {nd }}$ qualification.

It was not conducive or suitable to my needs or not interactive enough to facilitate learning process .... 


\section{Internal barriers impacting on the first attempt to acquire a tertiary qualification}

These included self-diminishing comments, self-doubt, fear of failure and low self-efficacy.

I'm one person who won't plan, I take any day as it comes .... I wouldn't wanna put myself in a situation whereby I would want to do something or pursue something, which at the end of the day due to affordability then I don’t for some reason.

... I think its dented already for some time now .... It's more like my ego now ... like if I meet with such an obstacle, knowing that I have received advices that I'd ... feel a bit bad ... I wanted to do this, but why didn't I finish it ....

\section{External locus of control}

Personal agency was affected by the contextual barriers:

... because based on the experiences that I've got, it's (self-efficacy) all dented and messed up because no matter what I wanted, no matter what I dreamt of, no matter what I would have like to have done ... I couldn't because of the obstacles ....

\section{Internal barriers impacting on attempts to acquire a tertiary qualification in middle-adulthood}

\section{Failure with later pursuits of a higher education qualification}

The abilities are there ... something that may perhaps be a distraction ... then giving up ... because maybe having interest elsewhere ... or thinking of something else.

... my mistake was I chose to study by distance learning, which I think disadvantaged me because I only received the study material and I was supposed to go through it.

I ended up ... quitting the project management. ... after 10 years of me studying.

\section{The shift: Changed perception of external barriers}

\section{Access to resources}

I didn't have access then, but I do now because the facilities that the $\mathrm{xxxx}$ has provided are ... there is a phone, a fax, there's internet, there's also my email ... whether doing personal things or work related.

... and now even my wife ... is also prepared to ... providing the same support if not more.

\section{Enhanced family image}

I cannot say it did because I managed to ... pass my Matric and I still managed to go post Matric even though I had ended up quitting here and there, but I still don't think it did impact on any of us because even my sibling now who is in Soweto, he's got his Matric ... he is doing his $3^{\text {rd }}$ Year now with his internship through xxxxx. 


\section{Acknowledgment of role models}

I remember two brothers ... I was still a student, he was a man of his family ... he was a translator in the court of law. One was a nurse, he also had his own family. ... I'd ... say .... I want to be like you ....

\section{Recognition of positive verbal persuasion}

My ex-colleague ... She'd always tell that ... '... you strike me as this person to whom nothing is impossible ....

An understanding that negative verbal persuasion can derail a person

Most people are saying, Law specifically is a bit difficult, but ... I want to try and delete the word difficult from my vocab?

\section{Changed perception of internal barriers}

\section{Decisiveness}

Confusion, making decisions? Not necessarily, because I would always try ... with most of whatever I was thinking of or maybe wanting to do, I would always run it past my mother, ... she would give positive advises.

\section{Internal locus of control}

... creating that little Stanza that will keep on pondering in my head that says ... Dude you need to do this ... you will see to it how you finish it .... So the self-efficacy can be improved.

\section{Framing his career trajectory and dreams differently}

My future career plans ... I'd want to become a successful person in any type of working environment ... The dreams ... working ... it shouldn't be about just the money ... the security ... It should be home next to home.

\section{His self-efficacy and outcome expectations}

... I would be able to overcome these obstacles.

It can be improved .... When it comes to abilities ...

I think I can ... if I'm able to do something .... So I think my self-efficacy can help me ...

\section{DISCUSSION}

The themes that emerged are informed by SCCT as espoused by Bandura (1986; 1993 and 1994). 
The participant, who is in middle-adulthood, still regards the external barriers presented by his childhood poverty which was exacerbated by the abovementioned compounding factors as the causes of his failure to obtain a tertiary education qualification during his first enrollment at a tertiary institution. This is consistent with the findings of Leroy and Symes, 2001 cited in Pellino (2007). He further confirms that his personal agency was affected by these contextual barriers making him feel worthless and helpless and impacting on his self-efficacy for studying. This external locus control precipitated by the participant's poverty status is consistent with SCCT (Bandura 1993).

The absence of the participant's father coupled with the chronic ill-health of his mother presented further challenges, especially with regard to available role models in his immediate environment. This is consistent with the respective findings of Sylvester (2010) and Callander and Schofield (2015).

The participant laments that his rural environment was deprived such that he lacked exposure and information at a crucial stage of his career development which resulted in lowered self-efficacy and lack of locus of control. This is consistent with Zinta's (2006) findings that adolescents from rural areas have lower self-efficacy due to a lack of exposure to enriched environments. This finding further mirrors that of Bernard, Dercon and Taffesse (2011) cited above regarding low self-efficacy, limited information from the outside world, lack of role models, a restricted world view, an external locus of control and not taking advantage of presented opportunities.

The participant recalls being an A student, but ascribes the drop in his school results to the challenges of adolescence. Spaull (2012), on the other hand, has criticized the education system's low quality education with a high and lenient grade progression until grade 11 as the root cause of the lack of systemic access to tertiary education for learners from disadvantaged contexts. The participant's rural status makes him especially vulnerable as these systemic challenges are more pronounced in rural areas.

The participant's submission to peer pressure and consequent abuse of alcohol to the detriment of his studies is in accordance with Maldonando's (2007) findings that lowered selfefficacy may lead to the abuse of alcohol in rural youth. This adverse impact of contextual factors on students' persistence and successful completion of their studies was observed in other South African studies (Bhorat et al. 2010) and internationally (Tinto 1997; Zajacova, Lynch and Espenshade 2005).

The results illustrate the far-reaching impact of perceived external barriers, also regarded as predictors, on obtaining a tertiary qualification: they may persist right into middle-adulthood 
despite the assertions of SCCT that maturity can enhance success (Bandura 1993).

With regard to his failure with later pursuits of a higher education qualification he confirmed that limited access to tertiary institutions due to course requirements, the requirement of additional tertiary qualifications for career advancement and the methods of instruction at the two institution's he attended constituted external barriers. This is consistent with the postulations of Bandura (1994) regarding the self-regulatory efficacy which is required in middle-adulthood to stabilize a sense of efficacy in major areas of functioning such as a spouse, a parent and a provider.

The participant's internal barriers in middle-adulthood presented as his fear of failure which manifested in avoiding disappointment by not making plans relating to pursuing a higher education qualification; blaming his failure in this regard on distractions, procrastination, the inability to focus and complete tasks and dependency when it came to decision-making relating to his studies. The low self-efficacy was context specific - relating to academic achievement. His goals, dreams, interests and outcome expectations relating to studies at institutions of higher learning suffered as a result.

A shift occurred with regard to the participant's internal perceived barriers, from external to internal locus of control, and he internalized how self-efficacy, in a triadic reciprocal way impacted his understanding of his world and career development by becoming more selfreflective, and aware, understanding that overcoming of barriers can happen. An understanding of the link between his goals (dreams), interests, outcome expectations, self-efficacy to career decision making and career direction and a clearer sense of personal agency emerged. This is consistent with SCCT as espoused by Bandura (1986; 1993; 1994).

Another shift was acknowledging positive changes in contextual influences conducive to positive outcome expectations. This manifested in an appreciation that his mother was a motivational force despite her chronic illness; that he had learnt vicariously from individuals who served as role models for him over the years; the current access to higher education and available resources to facilitate this process through his employer and the spousal support of his wife.

He acknowledged that a person can still achieve despite barriers and that increased maturity can facilitate a successful pursuit of a higher education qualification. However, the study produced an unexpected finding. The maturity of middle-adulthood did not diminish the impact of socio-economic variables which lowered self-efficacy in the participant's first attempt to pursue a higher education qualification. Faced with the new challenges of middle-adulthood as espoused by Bandura (1994) above, a shift in his perceived barriers causing his low self- 
efficacy only occurred after the participant sought a counselling intervention.

\section{Strengths and limitations}

\section{Generalizability}

The use of a single participant, chosen because of his willingness to participate, compromise the generalizability of the findings, since low self-efficacy may be a function of the participant who may not be representative of rural students in general (Agresti and Finlay 1997; Rubin and Babbie 1997, as cited in Creed, Patton and Prideaux 2006). However, the aforementioned authors concluded that research on the impact of career development interventions present unique challenges, like the level of control necessary to discern connections between career development interventions and student outcomes such as motivation and self-efficacy which may require the use of single subject design.

\section{Retrospective design}

The participant reflected on his high school and tertiary institution experiences and recalled his career development to date. This may be difficult, especially, if he is unable to recall isolated activities from this era. The participant's data may then be more a collection of those interventions and experiences that he recalls as being most significant, rather than the representative total quantity of his experiences and career development interventions (Delci and Stern 1999).

\section{Bias set of respondents}

The participant in the study may be a biased sample. He has already failed and dropped out. The research of the impact of the socioeconomic variables was targeted toward a participant with low self-efficacy from low a low socio-economic environment rather than examining how the socioeconomic variables affect students in general (Delci and Stern 1999).

\section{CONCLUSION}

The socio-economic variables mentioned above impacted on the perceived self-efficacy of the participant and his failure in the first pursuit of a tertiary qualification. These socio-economic variables are therefore predictors of success in this regard. Low self-efficacy from childhood can persist into middle-adulthood and be ascribed to new barriers relevant to that developmental phase. In light of the above it is concluded that counselling interventions are necessary in some instances for shifts to occur in middle-adulthood. 


\section{RECOMMENDATIONS}

Educators and counsellors need to be aware of the life-long impact challenging environments such as the one that the participant was exposed to has on the self-efficacy of learners and mediate them at all levels.

The author concurs with Spaull (2012) and Modisaotsile (2012) that systemic changes must be implemented at all levels in the South African educational system to eradicate and manage entrenched systemic challenges, including poverty. Regarding deprived rural environments this includes providing the required educational, counselling and information services through various means, including electronically supported enrichment programmes. The author further concurs with Redding and Walberg (2012) that at the local level rural schools and parents must recognize the lack of role models and engage in self-development programmes to promote vicarious learning.

Employers must similarly be aware that employees come from divergent backgrounds and create an awareness of the need for counselling services to increase self-efficacy in order to assist employees to navigate their career paths more efficiently.

\section{REFERENCES}

Babbie E. and J. Mouton. 2001. The practice of social research, 270-274. Oxford: O.U.P.

Bandura, A. 1986. The explanatory and predictive scope of self-efficacy theory. Journal of Clinical and Social Psychology 4: 359-373.

Bandura, A. 1993. Stanford University. Perceived self-efficacy in cognitive development. Educational Psychologist 28(2): 117-148. Lawrence Erlbaum Associates, Inc.

Bandura, A. 1994. Self-efficacy. In Encyclopedia of Human Behaviour. Volume 4, ed. V. S. Ramachaudran, 71-81. New York: Academic Press.

Bandura, A. 1997. Self-efficacy: The exercise of control, 184-194. W.H. Freeman \& Co.

Bernard, T., S. Dercon and A. S. Taffesse. 2011. Beyond fatalism - An empirical exploration of selfefficacy and aspirations failure in Ethiopia. Centre for the Study of African Economics: Department of Economics, University of Oxford, Oxford. http://www.iig.ox.ac.uk

Bhorat, H., N. Mayet, M. Visser, M. Cosser, M. Breier and M. Letseka. 2010. Student graduation, labour market destinations and employment markets, 124-142. Human Sciences Research Council.

Borman, G. D. and L. T. Rachuba. 2001. Academic success amongst poor and minority students: An analysis of competing models of school effects. Report 52, 1-24. John Hopkin University.

Braune, V. and V. Clarke. 2006. Using thematic analysis in psychology. Qualitative Research in Psychology 3(2): 77-101. ISSN 1478-0887.

Breakwell, G., J. A. Smith and D. B. Wright. 2012. Research methods in psychology. $4^{\text {th }}$ ed. SAGE Publications Ltd.

Callander, E. J. and D. J. Schofield. 2015. The potential for poverty to lower self-efficacy of adults with asthma: An Australian longitudinal study, allergy, asthma and immunology research. http://eaair.org 
Cosser, M. 2010. Pathways through the education and training system: Do we need a new model?, 119. Cape Town: HSRC Press.

Creed, P., W. Patton and L. Prideaux. 2006. Causal relationship between career indecision and career decision making and self-efficacy: A longitudinal study cross-lagged analysis. Journal of Career Development 33(1): 47-65

Delci, M. and D. S. Stern. 1999. Who participates in vocational programs? A preliminary analysis of student data from NLSY1997, 1-36. MDS-1300 Berkeley, CA: National Center for Research in Vocational Educational. University of California.

Fossey, E., C. Harvey, F. McDermott and L. Davidson. 2002. Understanding and evaluating qualitative research. Australian and New Zealand Journal of Psychiatry 36: 717-732.

Greenstein, R., B. Roberts and A. Sitas. 2003. Research methods training manual. (Unpublished) University of the Witwatersrand.

Loyd, K. M., M. Tienda and A. Zajacova. 2001. Trends in educational achievement of minority students since Brown vs Board. In Achieving high educational standards for all: Conference Summary, ed. C. Snow, 147-182. National Academy Press, Washington, DC.

Madhavan, S., N. W. Townsend and A. I. Garey. 2008. 'Absent breadwinners': Father - child connections in rural South Africa. Journal of South African Studies 34(3): 647-663.

Maldonado, R. M., L. J. Pedrao, M. M. A. Castillo, K. S. L. Garcia and N. N. O. Rodriguez. 2008. Selfesteem, perceived self-efficacy, consumption of tobacco and alcohol in secondary students from urban and rural areas of Monterrey, Nuevo Leon, Mexico. Latino-American Enfermagen 16(July/August): 614-620. Ribeirao Preto.

Maree, J. G. 2015. Barriers to access to and success in higher education intervention guidelines. South African Journal of Higher Education 29(1): 390-411.

Modisaotsile, B. M. 2012. The failing standard of basic education in South Africa. African Institute of SA, Briefing 72(March): 1-6.

Mok, M. and M. Flynn. 1997. Quality of school life and students' achievements on the HSC: A multi-level analysis. Australian Journal of Education 41: 169-188.

Neuman, W. L. 2003. Social research methods: Qualitative and quantitative approaches, 67-87. $5^{\text {th }}$ edition. Boston, Allyn Bacon.

Pajares, F. 1996. Self-efficacy beliefs in academic settings. Review of Educational Research 66: 543578.

Pellino, K. M. 2007. The effects of poverty on teaching and learning. http://www.teach-nology.com/ Articles/teaching/poverty/

Redding, S. and H. J. Walberg. 2012. Promoting learning in rural schools, 3-34. Center on Innovation and Improvement, Illinois.

Schunk, D. H. and J. L. Meece. 2006. Students' perceptions in the classroom. In Adolescence and Education Vol 5, ed. F. Pajares and T. Urdan, 71-96. Greenwich, CT, Information Age Publishing, Hillsdale, NJ: Larence Erbaum Associates.

Scott, I., N. Yeld, J. Hendry and M. Murray. 2014. Factors affecting graduation and student dropout rates at the University of Kwa-Zulu Natal. South African Journal of Science 110(11/12): Art \#2014-0008, 6 pages. http://dx.doi.org/10:1590/sajs.2014/20140008

Shank, G. D. 2002. Qualitative research: A personal skills approach, 18-32. Duquesne University, Merril Prentice Hall, Uppersaddle River.

Spaull, Nic. 2012, Education is SA: A TALE OF 2 SYSTEMS. Politics webs. www.politicsweb.co.za/ news-and-analysis/education-in-sa-a-tale-of-two-systems

Sylvester, F. J. 2010. At risk youth: Experiences of adolescent boys with absent fathers, 80-93. Department of Educational Psychology. University of Stellenbosch, Stellenbosch.

Tacoli, C., G. McGrahanan and D. Satterthwaite. 2015. Urbanization, rural-urban migration and urban 
poverty. IIED Working Paper, IIED London. http://pubs.iied.org/10725IIED

Tinto, V. 1997. Colleges as communities: Taking the research of student persistence seriously. Review of Higher Education 21: 599-623.

Zajacova, A., S. M. Lynch and T. J. Espenshade. 2005. Self-efficacy, stress and academic success in college. Research in Higher Education 46(6): 677-706.

Zinta, R. L. 2006. Performance among the high and low self-efficacious students. Journal of the Indian Academy of Applied Psychology 32(3): 255-263. 